\title{
Total Quality Management in Supply Chain Administration: An Analysis from Roads and Highways Department, Bangladesh
}

\author{
Ranapriya Barua \\ Roads and Highways Department, Cumilla Road Circle, Cumilla, Bangladesh \\ Email address: \\ ranapriyabarua@gmail.com

\section{To cite this article:} \\ Ranapriya Barua. Total Quality Management in Supply Chain Administration: An Analysis from Roads and Highways Department, \\ Bangladesh. American Journal of Engineering and Technology Management. Vol. 6, No. 1, 2021, pp. 10-15. \\ doi: 10.11648/j.ajetm.20210601.12
}

Received: February 19, 2021; Accepted: March 22, 2021; Published: April 16, 2021

\begin{abstract}
RHD, a public organization under the Road Transport and Highways Division of the Ministry of Road Transport and Bridges is responsible to enhance the traffic capacity and safety for efficient transshipment of goods and passengers on transnational boundary, national, regional, and Zilla highways. But in recent years the quality of works and services of RHD has failed to meet the standard required by the specifications. With this background the objective of this report is to evaluate the use of TQM tools to improve the performance of the supply chain in RHD. Primary data were collected through questionnaires survey from 34 engineers of different grades and secondary information were collected from the RHD website, journals, magazines, and different publications. Analysis shows to ensure quality in RHD it is necessary to conduct Quality Assurance Audit (QAA) through a third party. Also, an intensive and robust training program regarding TQM must be introduced for all levels of employees. Moreover, it is important to conduct studies with the uses of new technologies like IoT, AI, Block chain, etc. to improve quality-related difficulties and other supply chain processes in RHD to face upcoming challenge with the help of TQM approach in order to ensure value for money for the public fund.
\end{abstract}

Keywords: Total Quality Management, Roads and Highways Department, Quality Assurance Audit, TQM Implementation, Public Service Organization, Value for Money

\section{Introduction}

\subsection{General}

Quality means the degree of excellence. It is closely related to the customer's satisfaction. [6] Total Quality Management (TQM) has been used widely in many organizations, to enhance service quality. In Public services, implementing TQM is not necessarily part of its own activities. The government wants to implement quality management as a way to provide good service with full customer satisfaction. [3] TQM implementation in Public service organizations like RHD is quite challenging.

\subsection{Background and Rationale}

RHD is entitled to provide safe, cost-effective and wellmaintained road networks. [2] It is aiming to enhance the traffic capacity and safety for efficient transshipment of goods as well as passengers trafficked on national, regional, and Zilla highways. The government of Bangladesh has entrusted RHD with the responsibility of improving the quality of highways of national importance. But in recent years the quality of work and other activities has failed to meet the standard by specification. If it is allowed to continue, within a few years a significant amount of the existing RHD road network will deteriorate, which seriously hampered customer satisfaction. [5] RHD has run its quality management system. In order to upgrade the execution of the supply chain in RHD, it is ensured to evaluate the use of TQM tools and its system application hence the thesis topic is selected.

\subsection{Literature Review}

The literature review directed focuses on what quality is, 
quality standards, quality control, Total quality management, and as well as how to assess quality in the Roads and Highways Department. Before going detail on the topic the available literature related to quality is revealed. It is seen that exactly past literature related to RHD is little but regarding public sector organization like RHD are found available.

\subsection{Overview of RHD}

The Roads and Highways Department (RHD) was created in 1962 when the old 'Construction \& Building (C\&B) organization was divided into 2 separate bodies. The other organisation is Public Works Department (PWD). RHD is responsible for the construction and maintenance of the major road network of Bangladesh. Since the Department was established the size of the major road network in Bangladesh has grown from 4,500 km to the present network of $22,363 \mathrm{~km}$ [11].

The RHD is headed by a Chief Engineer who is supported by a variety of Additional Chief Engineers and also support by multilayer engineers. As for example SE, EE, SDE, AE \& SAE. It is responsible for an annual budget (2019-20) of Taka 20556.44 crore. Among them Development Budget Taka 18682.92 crore \& Revenue Budget Taka 1873.52 crore. The total number of posts in the Department is almost $9431[9,10]$.

\subsection{Whole Life Cost}

WLC takes road user cost into account. Disposal and recycling costs can also be included in WLC. As for example in Scarify, mix and recompact item RHD used old salvage materials. [12] By using this type of recycle materials can reduced total construction costs and also reduced environmental impact in road construction activities.

\subsection{Present State of Quality Control in RHD}

Quality Assurance Plan has been developed in RHD in 2005. The quality control tools are the tests required by the RHD general specification. RHD contractor with the technical specification is responsible for carrying out quality control tests. [4]

\subsection{The Current Situation and Way Forward}

RHD's responsible for road construction and maintenance. RHD is to be prepared to meet future demands by new capabilities. These modernized tools techniques like IoT, AI, Blockchain, new inspection, and testing systems. These will help to enhance the service quality of RHD and ensure users' satisfaction [12].

\section{The Present and Future Challenges of RHD}

\subsection{General}

The Roads and Highways Department (RHD) was created in 1962 when the old 'Construction \& Building' (C \& B) organization was split into 2 separate bodies, being Public Works Department. RHD is responsible for the construction and maintenance of the major road and bridge network of Bangladesh [1].

\subsubsection{Vision of RHD}

To build a Modern, Technology-based, and sustainable road network. [14]

\subsubsection{Mission of RHD}

To build a safe, cost-effective, sustainable, and environment-friendly road network by developing, expending, rehabilitating, and maintenance of highway in order to ensure the socio-economic development of peoples [14].

\subsubsection{Objectives of RHD}

To ensure development, rehabilitation, and maintenance of road network

To ensure \& expand the fast-moving public transport system.

To ensure safe road infrastructure

To established axle load control station to reduce pavement damaged [15]

\subsection{Personal}

The current sanctioned staff of the department totals 9431 comprising 688 class I, 888 class II, 4548 class III, and 3307 class IV post. However, RHD has a proposal total of 22380 nos. post in the new organization set up which consists of 2053 class I, 2554 class II, 9000 class III, and 8773 class IV employees [13].

\subsection{Budgets and Funding}

RHD spend a significant amount of government money for the development and maintenance of the road network. Maintenance and rehabilitation budgets will be based on the outputs of the HDM system. The department is also responsible for an annual budget of approximately $\mathrm{Tk}$. 20556.44 crore of which about Tk. 18682.92 Crore is for the Annual Development Budget and Tk. 1873.52 crore for the revenue budgets in the financial years 2019-2020 [9].

Five years ADP allocation, Maintenance allocation and income from toll are given below:

Table 1. Five years ADP allocation, Maintenance allocation and income from toll.

\begin{tabular}{llllll}
\hline Sl. No. & Financial Year & $\begin{array}{l}\text { Nos. of ADP } \\
\text { Project }\end{array}$ & ADP Allocation & $\begin{array}{l}\text { Maintenance } \\
\text { Allocation }\end{array}$ & Income from Toll-Bridge/Road/Ferry \\
\hline 1 & $2015-2016$ & 132 & 5990.32 & 1468.45 & 549.66 \\
2 & $2016-2017$ & 134 & 8199.28 & 1490.00 & 631.06 \\
3 & $2017-2018$ & 140 & 14144.68 & 2250.52 & 706.37 \\
4 & $2018-2019$ & 179 & 16118.85 & 2083.11 & 862.89 \\
5 & $2019-2020$ & 206 & 18682.92 & 1873.52 & 767.31 \\
\hline
\end{tabular}

Summarised by the author (Source-9: Annual Development Program for FY 2015-16, 2016-17, 2017-18, 2018-19 and 2019-20). 


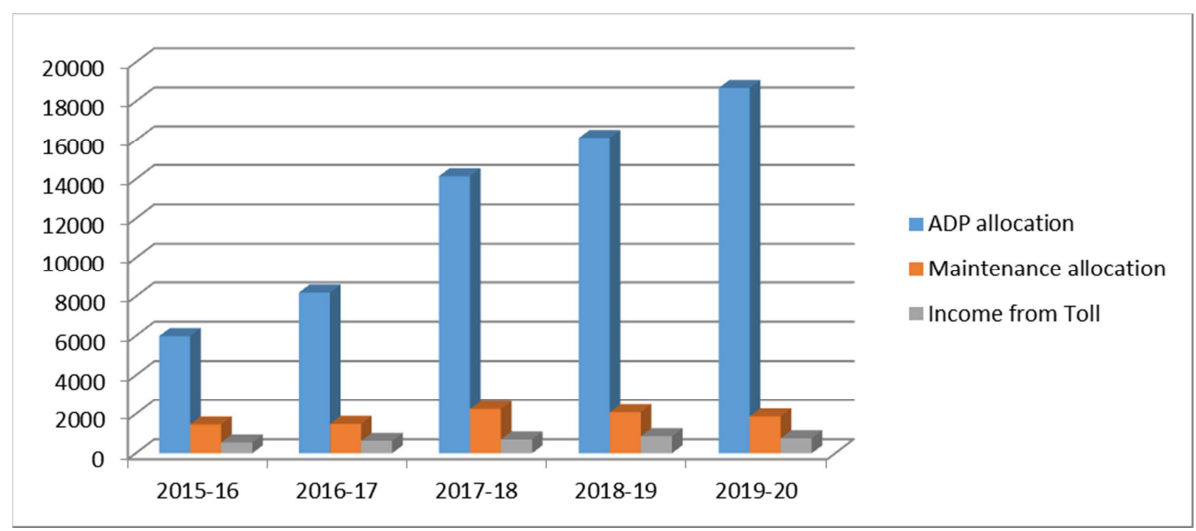

Summarised by the author (Source-9: Annual Development Program for FY 2015-16, 2016-17, 2017-18, 2018-19 and 2019-20)

Figure 1. Bar chart shows Five (5) year ADP, Maintenance allocation and income from Toll.

\section{Existing and Future Challenge of RHD}

\subsection{General}

Highway network carries nearly about $70 \%$ of all roadbased traffic in the country. Government-approved National Land Transport Policy (NLTP) in April 2004, where a longterm (20 years) Road Master Plan was emphasized. Accordingly, RHD prepared Road Master Plan under the guidance of ministry. It serves as a guiding document for the road sector investment priority Programme. It provides a physical plan for new road construction, rehabilitation, and maintenance programs. The present state of the RHD road network and the problems being faced in their effective development and maintenance. It was observed that the large sections of the network have inadequate structure strength, many of the damaged and narrow Bridge and Culverts need an immediate replacement, road pavement continues to get severely damaged by vehicle overloading. Traffic growth is also expected to be quite high [7].

Present problems and future challenges of RHD are summarised as:

Roads and bridges are continuously damaged from a lack of adequate maintenance and vehicle overloading Quality Challenges [7].

\subsection{Regional Road Connectivity}

In the process of globalization, the world has experienced surges of regional initiative in the last century. Strong connectivity not only strengthens the intra and inter-regional trade but also generates higher income and prosperity. Increased connectivity between South and South-east Asia can play an important role in achieving efficiency and enhanced productively. Transport connectivity along with trade facilitation measures may spur regional trade and commence by reducing the cost of transportation and logistics located in an advantageous geographical position (Regional Road Connectivity Bangladesh Perspectives, 2016).

In the process of promoting regional cooperation and integration; RHD is actively involved in different regional connectively initiatives namely, Asian Highway Network, South Asia Sub-regional Economic Cooperation (SASEC) Road corridors, Bangladesh-China-India-Myanmar Economic Corridor (BCIM-EC), Bay of Bengal Initiative for Multisectoral Technical and Economic Cooperation (BIMSTEC) Road Corridor, SAARC Highway Corridor, and Bangladesh, Bhutan, India, Nepal Motor vehicles agreement (BBINMVA) [8].

\section{Scope of Improvement Regarding Quality Issue in RHD}

\subsection{General}

The Government of Bangladesh (GOB) through Roads \& Highways Department (RHD) is aiming to enhance the traffic capacity and safety for efficient transshipment of goods as well as passengers trafficked on a national and regional highway section. The government of Bangladesh has entrusted Road and Highways Department (RHD) with the responsibility of improving the quality of highways of national importance [5].

The primary mandate of RHD is time and cost-efficient sustainable improvement of national highways from two-lane to four-lane, construction of new expressway, major bridges, fly over's, new grade-separated intersections and major underpasses on the national network. The maintenance of arterial roads, bridges, and culverts is to be completed in line with the quality of the highest standard. At present, the RHD owns the following national road network including bridges/ culverts [5].

Financial auditing of public-funded projects is performed under the present auditing system. The need for quality auditing arose from the fact that some of the recently implemented road construction projects have shown signs of either pre-mature failure and/or are in the process of failure before the design period. This quality provides a framework for conducting an audit [5].

\subsection{Quality Audit Plan}

Quality Audit Plan 
Table 2. Quality Audit Plan.

\begin{tabular}{|c|c|c|}
\hline Event & Needed documents or documents to be created & Persons/ Departments \\
\hline Audit start-Introduction, opening meeting & $\begin{array}{l}\text { - } \\
\text { - Management guidelines. } \\
\text { - Project quality assurance plan. } \\
\text { - Project super vision Consultant agreement. } \\
\text { - Contractor quality Assurance plan. } \\
\text { - RHD Organization with authority and responsibilities. }\end{array}$ & At Project Director's Office \\
\hline $\begin{array}{l}\text { Verification of the system of the organization } \\
\text { regarding: Management system }\end{array}$ & $\begin{array}{l}\text { - Client correspondence } \\
\text { - Environmental management plan }\end{array}$ & \\
\hline $\begin{array}{l}\text { documentation Project Review Processes and } \\
\text { interactions Objectives of the organization } \\
\text { Internal audits Performance data }\end{array}$ & $\begin{array}{l}\text { - Approved method statements. } \\
\text { - Approved QC plan. } \\
\text { - Approved ITP's (inspection and test plan in construction). } \\
\text { - Consultant review reports. } \\
\text { - Internal audit reports. } \\
\text { - NCR's details. } \\
\text { - Corrective Actions record. } \\
\text { - Preventive action records. }\end{array}$ & $\mathrm{SE} / \mathrm{EE} / \mathrm{RE}$ office \\
\hline $\begin{array}{l}\text { Verification of the system of the organization } \\
\text { regarding: } \\
\text { Project review } \\
\text { Processes and interactions } \\
\text { Plant and equipment } \\
\text { On site activities inspection } \\
\text { Performance data }\end{array}$ & $\begin{array}{l}\text { - Contractor quality assurance plan. } \\
\text { - Approved method statements. } \\
\text { - Calibration reports } \\
\text { - Site order book } \\
\text { - Approved } \\
\text { - Approved QC plan. } \\
\text { - Approved ITP's. } \\
\text { - Test reports \& MTC's (mill test certificate.) } \\
\text { - Equipment break down reports - Equipment ideal time reports } \\
\text { - Test reports \& MTC's (mill test certificate.) }\end{array}$ & $\mathrm{SE} / \mathrm{EE} / \mathrm{RE}$ office \\
\hline
\end{tabular}

(Source-5: Quality Audit Guidelines (QAG), 2017)

To achieve SDG's goal, implementation of roadmasters plan, and regional connectivity, the rapid development of sustainable quality transport infrastructure is the top priority. The most critical part is the implementation of a quality infrastructure implementation of a quality control management system in RHD will assist in achieving quality work. Quality audit is an important part of the quality control implementation system. So, it is Keen urgent of RHD to introduce quality audits by an impartial third party [5].

\section{Total Quality Management Practices in RHD: A Case Study}

\subsection{General}

The total quality management (TQM) process is considered as a modern system in the field of quality after quality control, quality assurance, and ISO in the public sector. In this study, where the questionnaires were distributed to 60 engineers through 'Google form' but questionnaires returned with completed form from 34 engineers. For analyzing purpose chi-square tests, frequencies, and response rates are used in this report. RHD's supply chain is extremely fragmented; its process is somehow different [16].

\subsection{Materials and Methods}

There are around 400 engineers work in RHD. Data was collected from these engineers with respect to the objectives and aims of this study. Out of the 60 Questionnaires that were the distribution to engineers, 34 engineers replied questionnaires which shows the response rate 57\% [16].

\subsection{Development of Questionnaires}

To find out TQM practice in RHD, in questionnaires, 38 nos of questions were prepared, which consist of six parts. Part one for the general information of respondent, part two for concern for TQM, part three considers a Quality perspective organizational improvement, part four for Data Acquisition of TQM, part five for Improvement strategy regarding quality and part six for others [16].

\subsection{Part One}

General Information: RHD is a specialized department of Government of Bangladesh, which main responsibility is to build roads, bridge and culvert, and ferry operations. At present, there is a different grade of graduate engineer works in RHD. They are Assistant Engineer, Sub-Divisional Engineer, Executive Engineer, Superintending Engineer, Additional Chief Engineer, and Chief Engineer. A total number of sanction post for graduate engineer were 523, but regular graduate engineer are around 400 . So, distributed questionnaires to 60 number engineers and questionnaires return from 34 number of engineers. In General Information there are name, job title, job role, present position, and overall experience. Distributed questionnaires to Assistant Engineer to Additional Chief Engineer. But as Executive Engineer, are working in mainly field level $22 \%$ of 
responded is Executive Engineers [16].

\subsubsection{Concern About TQM}

The perception of Quality was centered on conformance to standards as the majority of the engineer defined quality as a measure of conformance to standards. This affirmation the consequence of conformance to standards to the reaching of TQM in RHD. However, it is distress to observe that $33 \%$ of engineers believe that RHD has no formal quality management tools, and whereas $67 \%$ said that RHD has quality management tools. The reason for this might arise from the fact that there is a little misunderstanding of their belief that TQM will work in RHD; as a fifty percent (50\%) respondent replied that it works to some extent. It is, therefore, necessary for the authorities of RHD to emphasize the practice and improvement of TQM in its policies and regulations to ensure that all employees should be involved in it. Most of them (94\%) argued the benefits of TQM to there organization [16].

\subsubsection{Quality Perspective Organisation Improvement}

The engineers perceive product/service quality as important to the success of RHD. The perception of quality is such that they believe quality means the elimination of defects. Moreover, the majority ( $82 \%$ ) of them replied that service quality is very important to their organization. From this survey, it is shown that engineer emphasis on-site supervision $(21 \%)$, whereas only $9 \%$ importance on personal management of employee, for quality improvement, it is also noted that respondent ranked quality, safety and time as more important than cost and scope in project success [16].

\subsubsection{Data Acquisition of TQM}

Majority (53\%) engineers replied that they don't collect data to measure the performance of RHD. For quality-related problems, $41 \%$ of engineers answered that they set-up a multidisciplinary team. Regarding user satisfaction, most of them $(56 \%)$ said that it is very important for organizational improvement. It is encouraging to note that $36 \%$ of respondents are aware of the importance of quality and the majority of engineers (94\%) replied that RHD has QC/QA type qualify improvement program. This means that a lot of engineers of RHD are not aware of TQM in quality improvement programs in operational processes [16].

\subsubsection{Improvement Strategy Regarding Quality}

It was seen that no training regarding TQM is given to employees. It is only $12 \%$ whereas the majority (56\%) engineers believed that employee involvement is critical to successful TQM implementation. Regarding quality audit, most of the respondents (94\%) answered that they heard about quality audit and they firmly believed that (91\%) quality audit improve the performance of RHD [16].

\subsubsection{Others}

Most engineers (47\%) answered that RHD is taking the QA approach during construction works, whereas (44\%) replied that RHD is taken a QC approach. However, 79\% of engineers believed that RHD follows the 'Top-down' approach in decision making. From this study, it is observed that RHD is a bureaucratic organization whereas maximum decisions come from top-level management. Regarding the contractor's quality approach the majority of respondents said that there is no contractor's quality approach. When asked about obstacles in the implementation of the TQM program, it is seen that the respondent's emphasis on lack of education lack of expertise and lack of employee commitment are more important than the rigid attitude of engineers and too much documentation in the implementation of TQM program [16].

\subsection{Summary}

In conclusion, it can be said that RHD engineers are very much aware of TQM philosophy. However, they are well convergence with the benefit of TQM implementation and long-term outcome of TQM in RHD. It is seen that most of the engineers understand quality, quality improvement tools, and conformance specifications. But due to lack of proper training regarding TQM, they are not fully competent to implement TQM technique in their organization's operational processes. It is also seen that many public service organizations like RHD are pressurized by the government to try to implement TQM.

It is shown that there is a shortage in the data acquisition method. This is because in RHD there are no formulated systems for gathering user and employee's suggestions.

Finally, it is suggested that chaining the policy of training plan, and involving the third party for quality audit is to be the success of TQM implementation in RHD [16].

\section{Conclusion and Recommendation}

\subsection{Conclusion}

To achieve the Sustainable Development Goals in 2030, the rapid development of sustainable quality transport infrastructure is the topmost priority. The most critical part is the implementation of quality infrastructure. Implementation of quality control management systems like TQM in RHD will assist in achieving quality work.

It is observed from this study that within 10 years (20202030) RHD has to take huge pressure in terms of implementing the Road Master Plan, SDE's goal, and target and regional connectivity. In order to face these types of challenges, RHD should think of different approaches to provide its service to users, stakeholders in the utmost efforts. TQM is one of the approaches that RHD can take it to improve its quality-related challenges with the strategic leadership of Chief Engineer, RHD. The application of TQM may help RHD to assess the level of quality and to improve it. As RHD engaged in road and bridge construction and it is known that construction is one kind of production and its processes are a bit dissimilar. So, TQM is to be a useful tool in ensuring standards and successful development in the new construction, rehabilitation, and maintenance of road networks. TQM also enhance customer satisfaction, 
teamwork, efficiency attaining success against performance indicators than other public service organizations.

Moreover, TQM is a way of thinking about the right things are done right the first time; and a tool for improving the performance of whole organization.

\subsection{Recommendations}

Following Are the Recommendation of the Study RHD should think about carrying out third party quality audits of roads and bridge projects for ensuring continuous improvement in quality-related issues and as well as maximum benefit to the user/stakeholders.

RHD should take a robust and incentive training program regarding TQM implementation for all levels of employees for ensuring desired services from them.

Developing and improving the existing QAP to a TQM plan. Introduce dress code for all employees of RHD, which encourages employees to do their daily activities with more care and steady.

RHD should think about to improve its junction points with the construction of interchangers like cloverleaf/Diamond/trumpet and construction of NMV lane with crossing facility in all national Highway to increase mobility in transportation Sector.

RHD should conduct a further study with the uses of new technologies like IoT, AI, Blockchain, etc. to improve quality-related difficulties and other supply chain processes in RHD to faced upcoming challenges.

\section{References}

[1] RHD Manual, The People's Republic of Bangladesh, Ministry of Communications, Roads and Highways Department, July, 1994.

[2] RHD Management Plan, Volume-1, RHD Management Manual, Government of the People's Republic of Bangladesh, Ministry of Communications, Roads and Highways Department, December, 2003 (Issue-1).
[3] Author: Avia Enggar Tyasti, Rezzy Eko Caeaka, A Preview of Total Quality Management (TQM) in Public Services, EJournal Ekonomi dan Bisnis Universitas Udayana 6.9 (2017): 3285-3290.

[4] Quality Assurance Plan for Road work, Government of the People's Republic of Bangladesh, Ministry of Communications, Roads and Highways Department. April, 2005.

[5] Quality Audit Guidelines (QAG), Government of the People's Republic of Bangladesh, Ministry of Road Transport and Bridges, Roads and Highways Department. June, 2017.

[6] Quality Definition : Cambridge English Dictionary

[7] Road Master Plan, Volume-1: Main Text, RNIMP-2 project, Roads and Highways Department. June, 2009.

[8] Regional Road Connectivity Bangladesh Perspectives, Government of the People's Republic of Bangladesh, Ministry of Road Transport and Bridges, Road Transport and Highways Division. January, 2016.

[9] Annual Development Program for FY 2015-16, 2016-17, 2017-18, 2018-19 and 2019-20, Government of the People's Republic of Bangladesh. Planning Commission.

[10] Progress Report of Maintenance Works FY 2015-16, 2016-17, 2017-18, 2018-19 and 2019-20. Routine Maintenance Division. Roads and Highways Department.

[11] Annual Maintenance and Rehabilitation Needs Report 202021 for RHD paved Roads. HDM Circle, June, 2020.

[12] www.rhd.gov.bd.

[13] www.rthd.gov.bd.

[14] Annual Report, 2018-2019, Road Transport and Highways Division, Ministry of Road Transport \& Bridges, available at www.rthd.gov.bd.

[15] Annual Performance Agreement, APA 2018-2019 between Secretary, RTHD \& CE, RHD available at www.rthd.gov.bd.

[16] Ranapriya Barua, Total Quality Management Practices in RHD: A case study, International Journal of Engineering Research and Applications, Vol.-11, Issue-2, (series-II), 2021, pp. 18-30. 